\title{
Increasing English Communicative Competence through Online English Conversation Blended e-Learning
}

\author{
Murray J. Lawn and Etsuko Lawn
}

\begin{abstract}
In the field of increasing communicative competence in ESL (English as a Second Language) studies, practice with native speakers of English is ideal, but it is typically impractical for a variety of reasons in a University setting in Japan. However, for some time commercial English online conversation services have been used successfully by Japanese businesses in preparing staff for working in English speaking environments. This paper outlines the initial results of a university in Nagasaki making use of a similar online service as part of an ESL course in a blended e-learning format.

The online course required students to make appointments with the online service staff at times mutually convenient. The service consisted of one 25-minute lesson per one or two days. Initial observations by teaching staff noted increasingly high average levels of communicative competence in the pilot course students, and formal interviews confirmed this. Furthermore, resulting overall English grades were found to correlate closer to "time spent conversing in English online" than to "student initial pre-course scores."

A survey of the pilot course students was taken and the results are outlined in the paper. Student feedback uncovered a wide variety of problems ranging from lesson booking logistics, personal teacher preferences, and connection (Skype) problems; however, most comments were very positive regarding how they enjoyed speaking online in this blended e-learning environment. Increased motivation and a sense of making progress in being able to communicate better and with increased confidence in English were also commonly cited.
\end{abstract}

Index Terms-Blended e-learning, communicative competence, motivation, online English conversation.

\section{INTRODUCTION}

Recently, the use of online English conversation blended e-learning has been receiving increasing attention in Japan. The most commonly used service provider for Japan at present is the Philippines. As a part of a curriculum overhaul, the Department of English and Information Science at Nagasaki Junshin Catholic University decided to utilize on a trial basis a commercial online service as part of an ESL course for one term (of a two term year). The resulting significant increase in communicative competence in English exhibited by the students was the reason for writing this paper. As this was quite unforeseen, strictly empirical before and after testing procedures were not in place. Furthermore, being a "pilot course" this situation is not repeatable. Nevertheless, a number of assessment tools were in place including student

Manuscript received September 19, 2013; revised March 5, 2014.

M. J. Lawn is with the Medical-Engineering Hybrid Professional Development Program at the Nagasaki University Graduate School of Biomedical Sciences, 852-8521, Nagasaki, Japan (e-mail: lawnmj@hotmail.com).

E. Lawn is with Nagasaki University, Japan (e-mail: etsukolawn@hotmail.com). interviews, feedback from a student survey as well as teaching staff observations, all of which will be used to present the results. In regard to a control group, reference is made to classes of students with similar aptitudes in other departments as well as to prior class data.

\section{BACKGROUND}

Firstly, some important comments about the prevailing situation of university education in Japan will be presented. In general, motivation at high school is very high in order to enter the best possible university. Thus, the students work very hard towards scoring high on the National exam (Center exam - currently under review and is expected to be fundamentally changed within the next 5 years) whereby the level of university a student could enter will be decided. The level of university will have a major influence on the student's future employment prospects. In regard to this paper, several points must be noted: The National exam does not test "communicative competence" or writing skills and as such very few high schools make much effort in developing these. On the other hand, the Ministry of Education in Japan (MEXT - Ministry of Education, Culture, Sports, Science and Technology) is aware of the very poor, average level of English in Japan and has put in place national policies to encourage the advancement of "communicative English." Part of this initiative is the "JET" program (Japan Exchange and Teaching Programme) whereby English speakers from around the world are brought in to "team teach" with Japanese teachers at high schools.

In regard to university, the level of motivation to learn is typically considerably lower compared to high school, for most students' efforts during their time at university will go largely unnoticed, as it is primarily the level/name of the university that is significant [1]. Clearly, the motivation varies widely depending on the individual and also on the type of course that is being studied. Furthermore, in Japan public universities are generally ranked higher compared to most private universities. Next, returning to the subject of "English education," particularly communicative English, while some students have aspirations to work in an environment that requires English, the job prospects are slim for most graduates from lower level universities. Thus the aspect of "student motivation" is very important [1]-[3] in regard to teaching English particularly that of a communicative nature.

Currently the most commonly used English exam in Japan is the TOEIC exam, which does not require any communicative competence, while there is a TOIEC speaking writing exam; however, it is not widely used. The TOEIC test has come under increasing criticism in that high 
scores are typically achieved by learning advanced TOEIC exam taking techniques rather than learning English and many of the high scoring people are unable to communicate in English. Japan at the present point in time is the main user of the TOEIC exam worldwide, while most other countries have opted to include communicative competence or at the very least writing skills in assessment [4]. This situation is most likely to begin to change in the near future as the Japanese Prime Minister has indicated he wants to use the TOEFL exam, in order to include writing and speaking [5]; furthermore, the recent decision to host the 2020 Olympic games in Tokyo is also expected to increase further the motivation of students toward communicative English. Finally in the age of MOOCs (Massive open online course), disrupted classes [6] offer particularly low level students hope to be able to realize their potential despite getting off to a slow start. However most of this opportunity presupposes English competency, which brings us back to the need for both motivation and English.

Therefore, it is against a backdrop of overall low motivation in education combined with perhaps a low but increasing need for English, particularly communicative English, that the subject of using online English communication services as part of a university level ESL class will be introduced. Relating to "online English conversation" services, while there are at the present point in time at least 80 Japanese companies competing for the same Japanese customers, the Philippian companies tend to offer similar services at a lower cost. As for using Filipino teachers, although technically Filipinos are not native speakers of English, they are the 3rd highest users of English as an official language [7]. The service quality provided varies between companies and as can be seen from student comments vary significantly with the individual teacher. Some Filipino online conversation companies require teachers to be TESOL qualified. Furthermore, the simple fact that they (Filipinos) themselves have learnt English as a second language tends to make it easier for them to relate to Japanese students.

Similar studies carried out to date [7] (in Japanese) provide data of a more empirical nature regarding the relationship between "communicative competence" and the use of "online English conversation"; however, the number of students evaluated was smaller (21) and they were selected for a special course, focused on a combination of a certain teaching method in conjunction with the use of online English conversation. The resulting increase in TOEIC scores showed the lower level students increased the most, while higher scoring students showed little or no increase. It must be noted the "lower levels" discussed in that [7] paper are similar to the estimated TOEIC scores of all the students in this paper.

\section{METHODS}

All first year "English and Computing" major students in the Department of English and Information Science at the Nagasaki Junshin Catholic University, a private university in Nagasaki, were required to take commercially available online English conversation classes as part of a pilot course. The pilot course was carried out during the first term of a two-term year. The lesson times were arranged between the online service staff and the individual students. The service contract arranged between the university and the online service facilitated up to seven 25-minute lessons per week (one per day). However, although the department only required students to do at least four of these lessons, students were free to do all seven. Most students completed the four lessons required each week, while some students completed more, all of which is detailed in a later section of this paper.

As for the content of the lessons, there were a number of options provided. Firstly, students could choose on a per lesson basis whether to study "grammar", "free conversation", or "prepare for the TOEIC exam". Furthermore, they could choose between teachers who could or could not speak Japanese. Regarding the online material provided, most had Japanese explanations in faint small letters along with the English texts.

\section{RESUlTS}

The most significant result was the high level of communicative competence exhibited by the students. Based on observations by departmental staff including the author, the average level of communicative competence of the first year students was noted to exceed that of most other students from the same department who have studied English at the university for three and a half years.

Collected data included a standard class level test (SLEP Secondary Level English Proficiency test) taken before the beginning of the first term (of a two-term year). One month later a CASEC (Computerized Assessment System for English Communication) test was taken, and during the term the students were interviewed individually. The interviews were held in English and lasted typically four to five minutes. The content of the interviews typically began with small talk including a brief self-introduction and then, depending on the ability of the student reflected in the content to this point, the conversation was directed into increasing complexity until a limit was sensed, on which to base the interview performance. The author also gave short tests every week and then a final overall test, all tests and surveys given by the author were administered using Google forms. The overall evaluation reflects the student's overall performance throughout the term. Several radio theatre styled assignments were also included, refer to [3] regarding details on the radio theatre styled assignments.

A major part of this paper focuses on direct student feedback obtained through a survey. Reference is also made to the increased level of communicative competence as observed during both formal interviews and through informal interaction with the students. As mentioned previously, a number of tests were carried out, and correlations of various data sets were made. A correlation of overall student performance (throughout the term) was made to the number of online conversation lessons taken, and the resulting correlation was high (0.63). This correlation is of particular significance when compared with the correlation between the number of lessons taken and the student's initial SLEP test scores, which was relatively low (0.29). This indicates the student's final overall English score for the author's class more closely correlated to the number of conversation 
lessons taken than to the student's English level initially assessed.

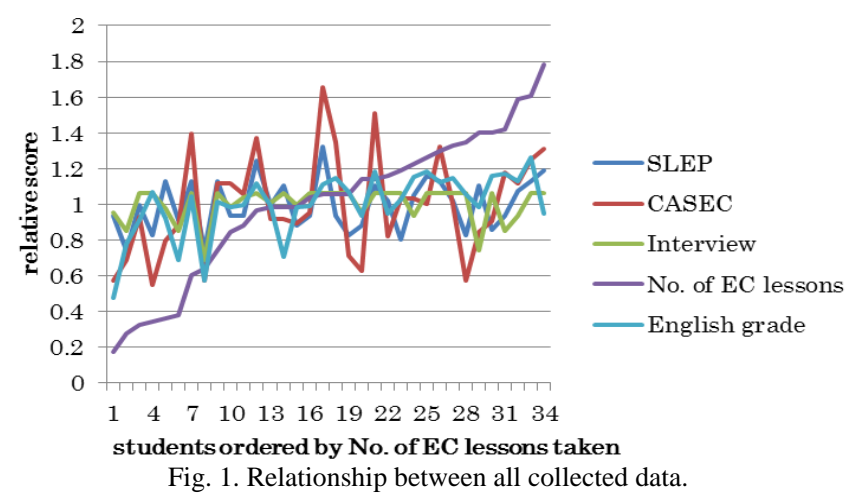

The complex relationship between the various data sets can be seen in Fig. 1 all data sets are normalized to an average of 1 .

\section{The student survey}

A summary of comments made by the students themselves in regard to their experiences in using the online conversation service as part of the pilot study is provided in this section. The number of respondents to the survey was 32 . The class total was 35 but three students were absent when the survey was taken. The survey was written and answered in Japanese for all questions and the answers have been translated into English.

1) Question 1. During the last three months how often did you use the online conversation service $\left(\right.$ Rarejob $\left.^{\mathbf{1}}\right)$ ?

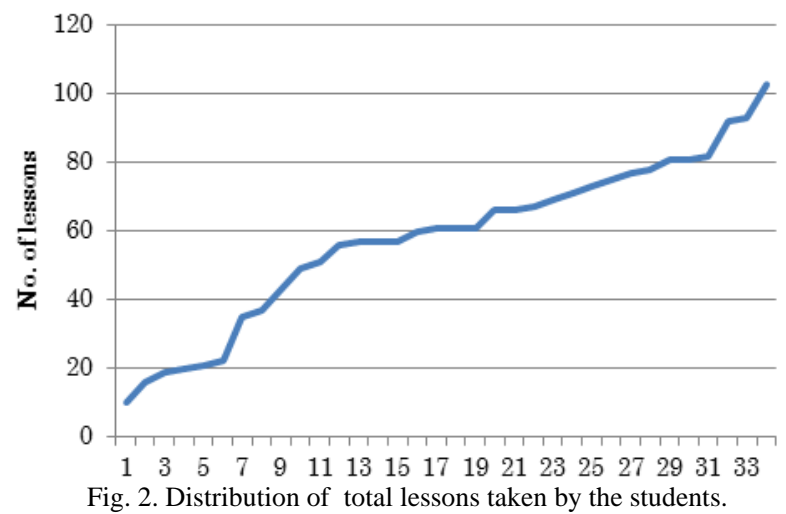

In regard to this question, answers were generally honest however, as a precise data record was available, the precise data is displayed in Fig. 2. This shows the distribution of the number of lessons taken by each student ordered from a few to many. The number of lessons required for a full score was 60 (4 lessons per week for 15 weeks), the maximum possible number of lessons was 122, and the average number of lessons taken was 56.

2) Question 2. Compared to April (the beginning of the term) do you feel that you have become more accustomed to speaking English?

\footnotetext{
1 "Rarejob" is the name of the online English conversation service provider used in the pilot course, it is based in the Philippians.
}

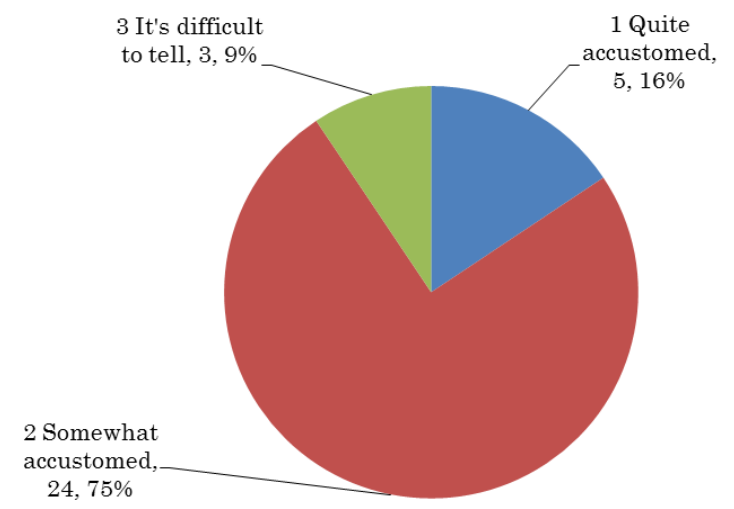

Fig. 3. How accustomed the students felt in speaking English.

The students' lack of awareness of how accustomed they had in fact become based on the interviews and general student interactions was quite surprising, although when seen through the eyes of Japanese culture regarding self-evaluation, it is not surprising. A simple illustration of this is if the author (a New Zealander) were asked "Can you play the piano", the answer would be a confident "Yes," because he learnt for 6 months or so when aged about 12 (and never practiced). However, when asking students a similar question but in regard to English, they would say "no" or "a little" despite having learnt it for 10 or so years (practicing several hours every day).

3) Question 3. Do you enjoy speaking English more now compared to April?

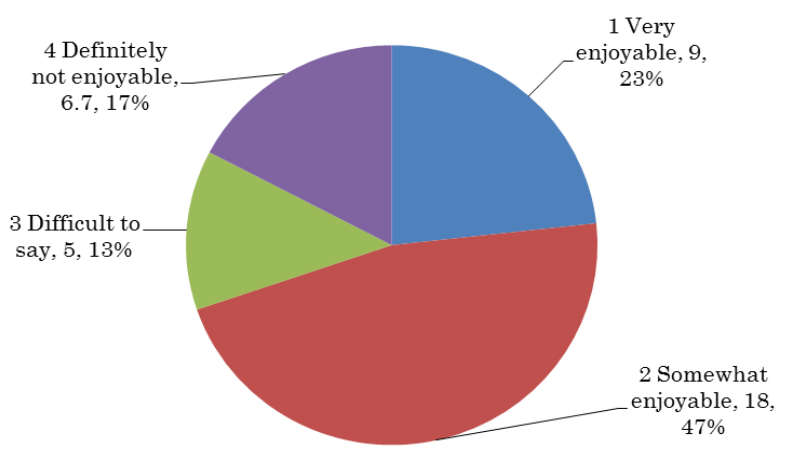

Fig. 4. Level of enjoyment in speaking English.

The data shown in Fig. 4 is reflected in Fig. 2. The number of lessons taken, however, in the final open question, all students indicated that it was enjoyable.

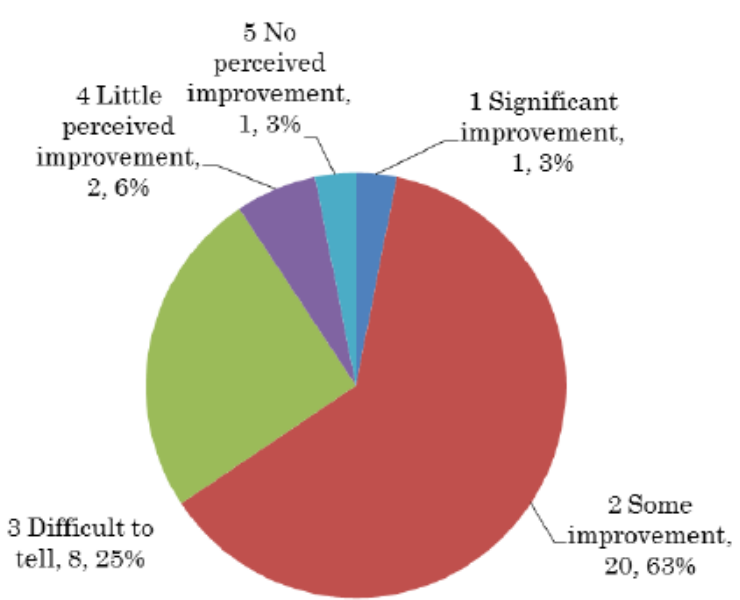

Fig. 5. Perceived improvement in English.

The same comment made regarding Fig. 2 applies to the 
tendency of the Japanese to underestimate when making self-evaluations.

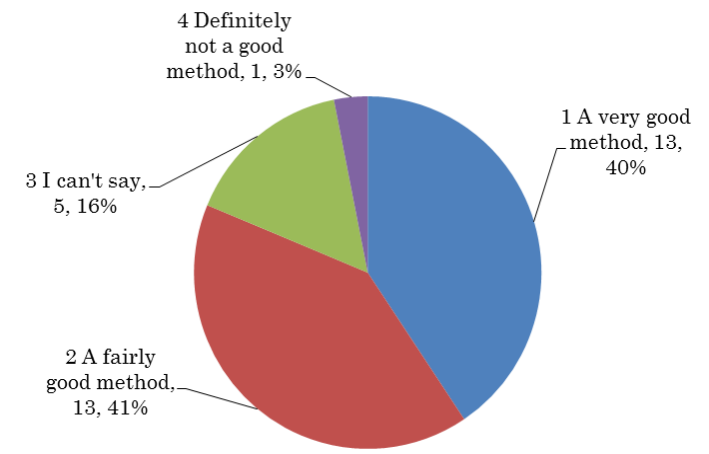

Fig. 6. Online conversation is a good way to practice English.

4) Question 4. Is online conversation a good way to practice English?

Most students agreed that it was either a "fairly good" or "very good" way to practice English. A fourth option "Not a very good method" was provided but not chosen by any students.

For Questions 5 through to 10 an open question format was used. Similar answers have been grouped together and the number of times similar answers occurred is indicated by e.g. " $\times 2$ " indicating that there were two similar answers. Furthermore in this section the author's comments or clarifications are noted in square brackets [ ].

5) Question 5. Regarding Question 4. if you answered that using online conversation is a "very good" or "fairly good" method to practice English, please write simply why you think it is "a good method."

- 25 minutes is short enough to be able to continue without tiring and it gives the opportunity to listen to real English pronunciation $\times 4$.

- Usually there is very little opportunity to speak with a native speaker of English, but the online conversation service has provided this opportunity, and furthermore, I can easily do it at home $\times 5$.

- I can choose a time that suits me and my favorite teacher $\times 5$.

- It's great that the online teacher will correct my way of speaking, pronunciation and grammar (using the chat function in Skype it was very easy to understand such corrections) $\times 4$.

- I have come to enjoy speaking to native speakers of English and this online service has made me want to study English more.

- I was asked to take 60 lessons by the teacher so I worked hard to take a lesson almost every day (unless this was required as part of the curriculum I wouldn't have taken the initiative myself) $\times 2$.

- Usually there is no opportunity to speak with native speakers of English. Although it was difficult understanding the online speakers, learning through listening to a native speaker of English is a great way to learn, I would like this online course to continue next year as well.

- As my English conversation time increases so also has my familiarity with speaking English.

- To attend an English conversation class (outside of university) is usually very expensive but as Rarejob (the online service used) is very reasonable and if one is motivated you can do it every day.

- This has allowed me to become familiar with both listening and speaking English but particularly I noticed my listening ability has improved.

- During class students are discouraged from speaking Japanese but on account of a lack of vocabulary and English expressions we cannot speak English well during class. Furthermore, any English used tends to be spoken with a Japanese accent. However, with Rarejob we can speak with a native speaker of English and some teachers will very carefully listen and repeatedly correct our mistakes. As a result, our English has improved.

- Although we do not speak to the teachers in person, since we do not usually have the opportunity to speak with native speakers of English, speaking online with such teachers compared to not doing so is very different.

- My hesitancy to even attempt understanding spoken English has largely reduced; however, I do not feel that my speaking ability has increased much.

- My hesitancy to speak English has gone and appropriate English words come to me naturally. This has been the very best thing to improve my English conversation skill. [Students' reduced response time when answering questions in English was one of the many significant results from this pilot study, typically after asking a student a question one braces one' self for a long wait or start to think how to reword the question or come up with assistive gestures etc. to get the message across without using Japanese].

- As Japanese in Japan we have very little opportunity to speak English. However, being able to easily use the internet, the short time of 25 minutes for the lesson and appropriate learning materials has made it easy to continue. It is a very good method and being able to use the chat function is also excellent.

- I always choose free conversation. I then do my utmost to make myself understood. As a result, I learn and remember new words and phrases making it a very good way to study. When I make a mistake I am immediately corrected via the Skype chat textbox function, which is a great method. Also, later I can review this material.

- As someone is directly listening to me, they correct me and explain the correct pronunciation. I can learn "living English" and learn from the Filipino teachers. [As a teacher the author is painfully aware that in teaching communicative English to a class of 40 to 50 students this is not possible, while some general mistakes can be corrected, to single out "a" student and correct "their" mistake in front of other students is not always best].

- There are very few opportunities to speak English at university but thanks to Rarejob I have the opportunity to speak English every day $\times 2$.

- Because as expected I can improve my ability to speak English.

- Usually we learn only grammar but do not go on to use 
it in real life, and at University there is a limit to what you can learn in three classes per week.

- You can only learn appropriate words, pronunciation etc. in an environment where you can speak with a native speaker of English every day. I did not choose "very good method" because I did not review the material. As I expected if you don't review the comments in the chat boxes you soon forget them.

6) Question 6. Regarding Question 4, if you answered "I can't say" whether using online conversation is a good method or not to practice English, please write simply why you think this way.

- I don't like the way that occasionally the teacher stops talking and ignores me.

- Because I can't see any significant change.

- I am used to speaking English but when I can't think of what to say I use translation software.

- I think this is a good way to learn English but it depends on the teacher.

- I think it is a good method and it is enjoyable, however my character is that when I do something I really do it but when I don't, I “don't." I haven't been doing it (taking the lessons) recently. I don't think it is good for people with my kind of character, because it is all up to one's self. I think Rarejob is really good.

7) Question 7. Regarding Question 4, if you answered that using online conversation is a "Not a very good method" or "Definitely not a good method" method to practice English, please write simply why you think this way.

- It is enjoyable but I don't think it will help me to be able to speak English.

[One person did not think it is a good method of practicing English at all, perhaps the option should have been provided to suggest better ways.]

8) Question 8. If you had any difficulties connecting using Skype or problems booking lessons please explain these problems.

- Some people always had difficulty connecting, while

- others had problems occasionally.

- Using a mobile phone (smart phone) always resulted in terrible reception.

- Sometimes despite booking a lesson, I was not called $x$ 3.

- Sometimes the line became disconnected part way through the conversation $\times 9$.

- Sometimes as the Skype voice reception was bad we just used the chat function.

- Occasionally there was a connection problem but it was solved.

- Sometimes I could see the video but could not hear the teacher.

- Occasionally there was static noise.

- I didn't have much trouble with the Skype connection.

- I was bothered by a teacher using the Skype chat function nearly every day to ask why I did not choose them as my teacher.

- Using a computer I didn't have trouble with calls dropping out like many of my friends but I did have such trouble when using my cellphone (smart phone) at home. If possible I would like that problem to be resolved.

- Sometimes I couldn't hear at all or the teacher would say that my side is noisy despite my being in a perfectly quiet place. It was probably just a bad connection.

- I am sad that recently the teacher that I like most is almost always fully booked.

- When the Philippians are experiencing a typhoon or such, the connections were bad and often lost.

- Five times I contacted them but received no reply. Sometimes even when I did book the lesson, it was not carried out. [Basically, the student has booked a time when the teacher is free and waits in front of the computer for the teacher to call on Skype but the teacher does not call.]

- Initially the line would often cut out but of recent I have not had such trouble.

- When I was using Windows 8, the settings were difficult so I could hardly do any lessons in April.

9) Question 9. What do you think of doing English conversation lessons online? (Required question).

- It's very easy to do and a good method but teachers did not always call me when they should have. This should be sorted out.

- On Wednesday I was unable to find a computer room that was available at a time that was convenient with Rarejob.

- Sometimes one is very busy but just 25 minutes is not too difficult to fit in somewhere. But often I could not get a teacher during my free time.

- I would like to continue online English conversation if I can find the money. Also, as there are not many computers in our department's computer room and senior students often seemed irritated by our using the service while they were studying, the school should provide an environment appropriate for this. [The senior students later said that they wished that they could have had this same opportunity (to use online English conversation at part of the course) when speaking with the author.]

- It's good but unfortunately when you are busy you can't do it.

- When you get a bad teacher your motivation to do another lesson drops.

- We must learn correct pronunciation and grammar but sometimes you get a strange teacher.

- There were some problems arranging times, but it is enjoyable. A lot depends on the teacher.

- Having the opportunity to speak English every day I feel my English skill has improved little by little. I resisted at first but once I got used to it I must agree it is a good method $\times 3$.

- I think it is good but it's a little expensive. By continuing it becomes even more enjoyable.

- I felt bound by Rarejob's times [the times range from 6 a.m. to 1 a.m. Japan time; however the student may be referring to teacher's availability]. Also, unless you do it every day, it is difficult to stay motivated.

- As there has never been such an opportunity to have English conversation outside of class, it is fun to be able to talk about each others' country's fashion and customs. [The opportunity to speak with someone from 
another country begins to create within the student a sense of identity as being "Japanese" and to begin to be able to express what it means - this is very important].

- 25 minutes seems to pass so quickly. It's very enjoyable.

- I was able to enjoy lessons with nearly all of the teachers. They were most interesting. If I make a mistake, it is corrected, I feel as if my English conversation skills are improving.

- At first I was hesitant but I am used to speaking English now, and I enjoy the lessons. I can read the teachers self-introductions and choose teachers with the same interests as myself. In fact, I feel as if I am talking to friends, and this has led to improving my self-confidence.

- Regarding listening to and speaking English, it is an excellent method. I have gotten used to speaking English and my hesitancy to use it has reduced. Sometimes I use English speaking to my friends during the day. But the teachers are divided into those I like and those I dislike.

- In order to improve one's English, it is important to listen to and speak English. Therefore, online English conversation is a very good method.

- Rarejob is a great way. Initially I was hesitant until I got used to it, but now I really like it.

- The lessons are great and I think my English has improved. But because I am busy and cannot book times when I am free and as the lessons relate to my grades, I think it is unfair. If possible I would like to be able to do it during class. [This is a good point worth considering, in the study in [7] the conversation time was built into class time as is usually the case in blended e-learning].

- Enjoyable but I felt it to be somewhat meaningless. [This student probably needs to have a real "meaningful" purpose].

- As I love speaking English to foreigners, through this I feel I have made many English-speaking friends. If this was free, I would like to continue using it.

- As there are few opportunities to speak with foreigners, being able to speak with them so easily is very convenient.

- Since using Rarejob I have made significant progress in being able to quickly put English sentences together in my head and I am able to speak English.

- My reluctance to speak English has reduced.

- Please continue the program!!!

- Since I have become used to it I have chosen "free conversation". However, one teacher recommended that I do "grammar", so I have been doing that. Previously I felt I was making progress, now I do not feel that, but I feel my English is better than before. Continuing in this manner I feel uneasy but I wish to do my best.

- Until now I couldn't face making a booking for a long time. When I finally got around to book someone, no one was available so I didn't do it. Rather than feeling it was a bother I should just give it my best as it is in my own interests.

- I feel sad when I have an unfriendly teacher.
- I enjoy English conversation every day. The Filipino teachers always laugh. By having the same teacher over and over, conversation becomes easier, I get to know them well and look forward to the next lesson. 25 minutes seems to pass before I know it.

- Recently I feel I would like to go to the Philippians at some stage.

- I would like to work overseas as a volunteer.

- I have added "Online English conversation" to my list of interests.

- I have come to enjoy English conversation and wish to become even better at it. I would like to be able express even better what I think, my motivation has increased, and feel being able to speak English naturally is amazing!

- This is excellent, even when the school's course has finished I plan to continue.

- When I feel motivated, I do it every day of the week, but when I don't feel motivated, I don't do it at all. My emotions are like this. Regarding improvement with English conversation, as expected I don't feel I am improving.

- When I get a good teacher, I wish to continue, but unfortunately it's a hit and miss situation. I can't find or can't book my favorite teacher because their schedule is full and it's disappointing to end up speaking the same content time after time.

- Initially it was inevitably a pain, but once I found a teacher that suited me, my English conversation has improved to the point of being able to tell jokes.

- I thought that there was no way I could speak English but the teachers were very kind, explained things and listened carefully to my poor English, making me very happy.

- Depending on the teacher, some are motivating while others are not. As the university is paying for this, it should be sorted out.

- I think these lessons are great for people who will use English in the future. However, no matter what continuing these lessons is important.

- Even after doing lessons for half a year I have not become used to them. In this regard, missing a daily lesson seems a waste.

- When I have a good teacher, it is very fruitful, and by a good teacher I mean one who corrects my pronunciation and uses the text box function. When I don't have this kind of teacher, I feel sleepy.

\section{DISCUSSION}

In regard to the very complex nature of the relationships between the data in Fig. 1, correlating all data with the number of conversation lessons taken, part of the complexity may reflect in part the inherent tendency of an inverse relationship between students that diligently study and those who like to talk.

The high correlation between the number of online lessons taken and overall course performance while having a lower correlation with the initial scores could be interpreted various ways. Firstly, the simplest explanation is the increased number of lessons either increased overall student 
performance, the lessons motivated the students to study more or finally a combination of both of these. A typical complaint of Japanese students regarding English is that despite six to nine years of English study most could not tell you their phone number in English if you asked them for it [8], which is near zero communicative competence. However the author of this paper is very confident that these students would pass this task test with room to spare based on personal interviews with each of the students. Regarding interviews with the students of this pilot class, they on average surpassed previously conducted interviews. This was based on the author's previous seven years or so of experience having interviewed students in a similar manner. There were however some exceptions, as follows; 1 . Students who had spent 6 months to one year on a homestay English study program in New Zealand - available to the top students in the author's department. 2. Medical students at Nagasaki University where the author is a visiting Lecturer, having overall very high level academic ability.

In the author's department there are a large number of native speakers of English on the teaching staff (5) compared to most private universities (often 1-2). However, with typical class sizes of 40 students, the time spent one on one is very little. There are other opportunities to speak with teachers outside of class but nothing to compare with 56 (on average) 25 minute one on one lessons with near native speakers of English online. From the author's personal experience in taking students on study trips overseas, 25 minutes may reflect average daily conversation with native speakers of English in the case of individual student homestays. The author recalls speaking with his son when he was attending a school in New Zealand for one month, when asked what English he spoke during an entire day his response was “can I borrow your eraser?" In many situations, the Japanese are often very hesitant to use any English irrespective of how good or bad it is, and as a result the level of communicative competence does not improve irrespective of how much they study. There are of course, on the other hand, a few students who are very outgoing by nature and truly make the most of every opportunity to speak English no matter what, and these few do very well.

One native speaker of English teacher made the following comment regarding the students of the pilot course: "A perceived increase in their ability to put sentences together with more confidence and generally not giggle foolishly at the mere fact they're communicating in English. Of course, there are other factors contributing to this improvement, such as our teaching." "Giggling" or laughing is what young Japanese females particularly do when they are embarrassed, in this situation it may have indicated that they were not confident.

The author observed a number of online conversations, during such activities as free conversation the teacher and student would often exchange website links to assist in the showing or explaining of things difficult to visualize. The author thought this was an innovative idea, similar to Facebook styled conversations.

As for the choice of Japanese speaking versus non-Japanese speaking teachers, one student said she choose a teacher capable of speaking Japanese but later changed to a
non-Japanese speaking teacher when she realized she ended up speaking Japanese. The author thought this was a very mature decision, many Japanese students travel abroad to improve their English and spend most of the time speaking with Japanese friends or local Japanese staff in Japanese.

\section{CONCLUSIONS}

A pilot course using a commercial online English conversation service in a blended e-learning format was used to supplement regular ESL lessons at a private university in Nagasaki Japan. This experience provided the students with the unique opportunity to be able to speak one on one with near native speakers of English. Use of this service required the students themselves to take the initiative to choose and book a teacher for 25 minute lessons, every one or two days, and to choose what kind of lesson they wished to take. While nearly all students experienced some degree of reluctance to get started they all overcame this to become significantly more confident in speaking English.

A number of problems were encountered; this included Skype connection problems, logistical problems coordinating their available time with an available computer/ room and finding a teacher who was also available at that time, furthermore not just booking any teacher but their "favorite teacher".

Based on direct student feedback and teaching staff observations including English interviews, the supplementary lessons provided significant motivation to learn English, increased English communicative competency and has increased student's overall self-confidence. Additional benefits also included developing a sense of identity being Japanese, as most of them for the first time had the opportunity to speak about Japan and what it meant to be Japanese.

\section{REFERENCES}

[1] K. Aoki, "The use of ICT and e-learning in higher education in Japan," World Academy of Science, Engineering and Technology, vol. 42, 2010, pp. $854-858$

[2] I. Inage, E. Lawn, and M. Lawn, "Reflections on the use of original dramatized presentations in the classroom: based on direct student feedback," Bulletin of Faculty of Education, Nagasaki University: Curriculum and Teaching, no. 51, March 2011, pp. 93-108.

[3] I. Inage, E. Lawn, and M. Lawn, "An analysis of student motivation in an ESL classroom by using a movie and reader's theatre styled assignments-based on student feedback," Bulletin of Faculty of Education, Nagasaki University: Curriculum and Teaching, no. 53, March 2013, pp. 51-63.

[4] Getting away from the TOEIC, Just studying for the TOEIC exam doesn't improve your English, Weekly Toyo Keizai, pp. 34-35, 2012, June (in Japanese)

[5] J. Hongo. (March 25, 2013). Abe wants TOEFL to be key exam. Japan Times. [Online]. Available: http://www.japantimes.co.jp/news/2013/03/25http://www.japantimes. co.jp/news/2013/03/25 /national/abe-wants-toefl-to-be-key-exam/

[6] C. Christensen, M. Horn, and C. Johnson, Disrupting Class: How Disruptive Innovation Will Change the Way the World Learns, $2^{\text {nd }}$ ed., New York: McGraw-Hill, 2011.

[7] K. Saki, N. Takaki, S. Yamamoto, and Y. Kudo, "The educational effects of online English conversation and a proposed method for measuring the results," Next Generation Education Research, Osaka University of Economics, no. 68, April 2010, in Japanese.

[8] G. Clark. (September 30, 2010). Saving Japan's universities. Japan Times. [Online]. Available: http://www.gregoryclark.net/jt/page75/page75.html 


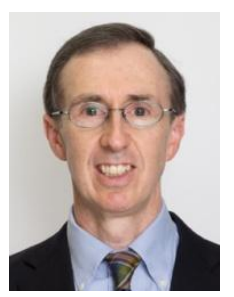

Murray J. Lawn received a degree in electrical engineering at Canterbury University, New Zealand in 1989, and a Ph.D. in electrical and mechanical engineering at Nagasaki University Japan in March 2003. He worked as a technician and later engineer for the New Zealand Railways, then as a communications consultant for NZ Telecom. In 1994 he came to Japan where he has taught Technical English, Multimedia, e-learning, and computer science at the Nagasaki Institute of Applied Science, Nagasaki Junshin Catholic University and Nagasaki University. He is currently working as Engineering coordinator for a Medical-Engineering Hybrid Professional Development Program at the Nagasaki University Graduate School of Biomedical Sciences.

Dr. Lawn (MIEEE) received prefectural awards for innovation (stair-climbing wheelchair) in 1997 and 1998. Studies and interests include the development of medical instruments, rehabilitation devices, and the effective use of CALL, ICT and e-Learning systems and multimedia in education.

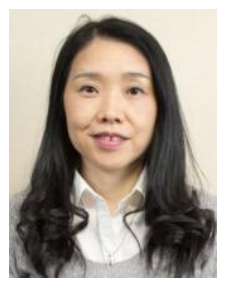

Etsuko Lawn received a junior college degree in British - American studies at the Nagasaki Junshin Junior College, Japan in 1978, studied at Canberra College of Advanced Education, Australia until 1981, received a degree in education from the Open University of Japan in 2001 and a master's degree in English education in 2007 at Nagasaki University, Japan. She worked in banking in Japan and New Zealand, then worked for the Japanese Embassy in the Japanese Culture Center in New Zealand before returning to Japan in 1993 where she currently works part time as a visiting lecturer at Nagasaki University. Studies and interests include the motivation of Japanese students in regard to English proficiency, and the effective use of CALL, ICT and e-Learning systems in education. 